Temporal variability of visibility and its parameterizations in Ningbo, China

Jingjing Zhang, Lei Tong, Chenghui Peng, Huiling Zhang, Zhongwen Huang, Jun He, Hang Xiao
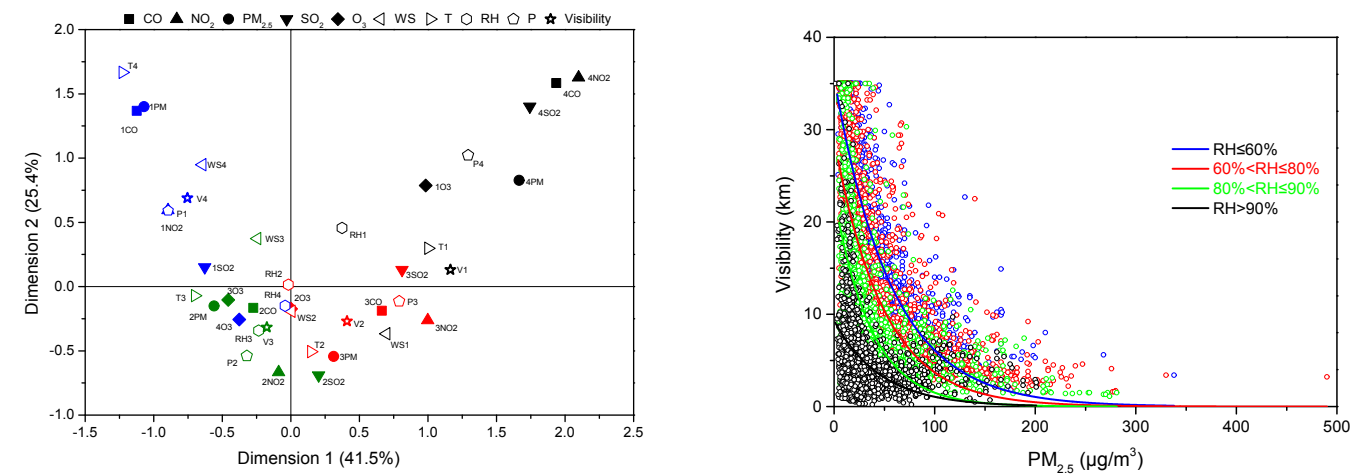


\section{Temporal variability of visibility and its parameterizations in Ningbo, China}

\section{Jingjing Zhang ${ }^{a, b, c, 1}$, Lei Tong,b, ${ }^{a, b}$ Chenghui Peng ${ }^{b, c}$, Huiling Zhang ${ }^{a, c}$, Zhongwen Huang ${ }^{\mathrm{a}, \mathrm{c}, \mathrm{d}}$, Jun $\mathrm{He}^{\mathrm{e}}$, Hang Xiao ${ }^{\mathrm{a}, \mathrm{b}, *}$}

${ }^{a}$ Center for Excellence in Regional Atmospheric Environment, Institute of Urban Environment, Chinese Academy of Sciences, Xiamen 361021, China

${ }^{b}$ Key Lab of Urban Environment and Health, Institute of Urban Environment, Chinese Academy of Sciences, Xiamen 361021, China

${ }^{c}$ University of Chinese Academy of Sciences, Beijing 100049, China

${ }^{d}$ School of Chemistry and Environmental Engineering, Hanshan Normal University, Chaozhou, 521041, China

${ }^{e}$ International Doctoral Innovation Centre, Department of Chemical and Environmental Engineering, University of Nottingham Ningbo China, Ningbo, China

*Corresponding author. Institute of Urban Environment, Chinese Academy of Sciences, Xiamen, China.

E-mail address: hxiao@iue.ac.cn

${ }^{1}$ The authors contributed equally to this article. 


\title{
Temporal variability of visibility and its parameterizations in Ningbo, China
}

\author{
Jingjing Zhang,b,c, , Lei Tonga,b,1, Chenghui Peng, ${ }^{\mathrm{b}, \mathrm{c}}$, Huiling Zhang ${ }^{\mathrm{a}, \mathrm{c}}$, \\ Zhongwen Huang ${ }^{\mathrm{a}, \mathrm{c}, \mathrm{d}}$, Jun He ${ }^{\mathrm{e}}$, Hang Xiao ${ }^{\mathrm{a}, \mathrm{b}, *}$ \\ ${ }^{a}$ Center for Excellence in Regional Atmospheric Environment, Institute of Urban Environment, \\ Chinese Academy of Sciences, Xiamen 361021, China \\ ${ }^{b}$ Key Lab of Urban Environment and Health, Institute of Urban Environment, Chinese Academy \\ of Sciences, Xiamen 361021, China \\ c University of Chinese Academy of Sciences, Beijing 100049, China \\ ${ }^{d}$ School of Chemistry and Environmental Engineering, Hanshan Normal University, Chaozhou, \\ 521041, China \\ e International Doctoral Innovation Centre, Department of Chemical and Environmental \\ Engineering, University of Nottingham Ningbo China, Ningbo, China
}

Abstract: Simultaneous and continuous measurements of visibility, meteorological parameters and the concentrations of six atmospheric pollutants $\left(\mathrm{PM}_{10}, \mathrm{PM}_{2.5}, \mathrm{SO}_{2}, \mathrm{NO}_{2}, \mathrm{CO}\right.$ and $\left.\mathrm{O}_{3}\right)$ were determined at a suburban site of Ningbo, Eastern China from June 1, 2013 to May 31, 2015. The characteristics of visibility and relationships with air pollutants and meteorological factors were investigated using multiple statistical methods. Daily visibility ranged from $0.6 \mathrm{~km}$ to $34.1 \mathrm{~km}$, with a mean value of $11.8 \mathrm{~km}$. During the 2-years' experiment, $43.4 \%$ of daily visibility was found to be less than $10.0 \mathrm{~km}$ and only $9.2 \%$ was greater than $20.0 \mathrm{~km}$. Visibility was lower in winter with a frequency of $53.4 \%$ in the range of $0.0-5.0 \mathrm{~km}$. Annual visibility had an obvious diurnal variation, with the lowest and highest visibility being $7.5 \mathrm{~km}$ at approximately 06:00 local time and $15.6 \mathrm{~km}$ at approximately 14:00 local time, respectively. Multiple correspondence analysis (MCA) indicates that visibility shows significant correlations with concentrations of pollutants and meteorological conditions. Based on the analyses, visibility is found to be the exponential function of $\mathrm{PM}_{2.5}$ concentration within a certain range of relative humidity. Thus, non-linear models combining multiple linear regressions with exponential regression were subsequently developed using the data collected from June 2014 to May 2015, and the data from June 2013 to May 2014 was used to evaluate the performance of the model. It was demonstrated that the derived models can quantitatively describe the relationships between visibility, air quality

\footnotetext{
*Corresponding author. Institute of Urban Environment, Chinese Academy of Sciences, Xiamen, China. E-mail address: hxiao@iue.ac.cn

${ }^{1}$ The authors contributed equally to this article.
} 
and meteorological parameters in Ningbo.

\section{Introduction} 1999; Horvath. 1995).

Keywords: Visibility; Multiple correspondence analysis (MCA); Multiple non-linear regression

Horizontal visibility is defined as the greatest distance at which a black object can be visually identified with unaided eyesight against a light sky (Wark et al. 1998; Watson 2002). In the absence of unusual weather, the reduction of visibility is an important indicator of deteriorating ambient air quality which has become a serious environmental issue of public concern in populated cities and has been reported to have adverse effects on human health, crop growth and traffic safety (Che et al. 2006). It has been widely confirmed that the impairment of visibility is mainly due to the scattering and absorption of visible light by suspended particles (Chan et al.

Atmospheric particulate matter (PM) is associated with both anthropogenic and natural emissions that consist of minuscule particles of solid or liquid matter, with diameters ranging from $0.01 \mu \mathrm{m}$ to $100 \mu \mathrm{m}$. Atmospheric particles can affect the climate by both direct and indirect radiative forcing (Charlson et al. 1992; Xu et al. 2002), especially fine aerosols with aerodynamic diameters of $2.5 \mu \mathrm{m}$ or less $\left(\mathrm{PM}_{2.5}\right)$. The smaller a particle, the longer it will remain suspended in atmosphere and impact the environment over greater distances. In addition, many studies have shown that fine particles, which include sulfates, nitrates, organic and elemental carbon, could effectively scatter or absorb visible light and thus reduce visibility (Zhang et al. 2012; Kim et al. 2006; Tan et al. 2009a, 2009b). All these airborne particles, together with other gaseous pollutants such as sulfur dioxide $\left(\mathrm{SO}_{2}\right)$ and nitrogen oxides $\left(\mathrm{NO}_{x}\right)$ could contribute to the increase of haze and lead to a low visual range ( $\leq 10$ kilometers). Specifically, the heterogeneous aqueous 
64 transformation from $\mathrm{SO}_{2}$ and $\mathrm{NO}_{x}$ is enhanced during haze episodes, which probably leads to the 65 remarkable secondary formation of sulfate and nitrate in fine particles, further impairing visibility

66 (Wang et al. 2006). In addition to air pollutants, many meteorological parameters such as relative 67 humidity (RH), wind speed (WS) and direction (WD), temperature, pressure and precipitation can 68 also contribute to light extinction and degrade air quality (Zhao et al. 2011; Yang et al. 2007). In 69 haze events, the rapid increase of PM concentrations, high RH, and low WS, can simultaneously 70 adversely impact atmospheric visibility (Tsai, 2005; Zhang et al. 2010; Deng et al. 2011). As RH 71 increases, hygroscopic particles progressively absorb more moisture, which will increase the 72 scattering cross section of aerosols and proportionately reduce visibility. Therefore, RH could 73 directly affect the particles that contribute to visibility reduction. While other meteorological 74 variables such as WS, temperature, and pressure have indirect effects on visibility, they may also 75 affect the concentration of atmospheric particles due to the thermal and mechanical turbulence 76 (Du et al. 2013). The accumulation and transport of particles are closely related to the synoptic 77 systems and atmospheric circulations. Tsai (2005) identified that conditions for reducing 78 visibility included high atmospheric pressure, low WS, and low mixing layer height. Deng et al. 79 (2011) have also highlighted the significant impact of synoptic systems on air pollution and 80 visibility in Nanjing.

81 The forecasting and early warning of visibility, which mainly based on the relationships 82 between air pollution and light extinction, is not only very important for environment and public 83 health, but also for traffic control and even military. A number of models were previously 84 developed to describe the correlations between visibility and air pollution, and much continuous 85 efforts have been made to improve the models based on the monitoring results of visibility meter. 86 Wen and Yeh (2010) established multiple linear regression equations linking visibility and 87 atmospheric air conditions for data collected in Taiwan. Both Lin et al. (2012) and Tsai (2005) 
88 developed empirical regression models for visibility, with a logarithm of coarse particle 89 concentration used in the regression analyses. Additionally, several studies have suggested that 90 visibility is a linear response to the exponential function of $\mathrm{PM}_{2.5}$ concentrations under a certain

91 RH range (Cao et al. 2012; Yu et al. 2016; Shen et al. 2016). All these studies suggested that the 92 impacts of air quality and other variables on visibility are more complicated than linearity and 93 need to be studied further.

94 In recent decades, four major regions in China (i.e. Beijing-Tianjin-Hebei region, the Yangtze 95 River Delta (YRD) region, the Sichuan Basin, and the Pearl River Delta (PRD) region), have 96 experienced a severe loss of visibility (Zhang et al. 2012). Ningbo is one of the most highly 97 urbanized and industrialized cities in the YRD region and had a population of 7.87 million people 98 and a vehicle fleet of 1.98 million by the end of September 2016. The city is located in the south 99 of Hangzhou Bay and to the west of the East China Sea with an area of $9816 \mathrm{~km}^{2}$. With a rapid 100 urbanization and an increase in motor vehicle numbers, Ningbo energy consumption has 101 increased substantially and haze events have been frequently observed in recent years (He et al. 102 2016; Cheng et al. 2014; Hua et al. 2015). Local visibility might be significantly influenced by 103 the increasing frequency of haze episodes. However, there have been few studies focusing on the 104 characteristics of visibility, and their relationships with air pollutants in Ningbo.

105 In this study, visibility was monitored from June 2013 to May 2015, with potential 106 relationships between visibility and a range of air pollutants (i.e. $\mathrm{SO}_{2}, \mathrm{NO}_{2}, \mathrm{CO}, \mathrm{O}_{3}, \mathrm{PM}_{10}$, and $107 \mathrm{PM}_{2.5}$ ) and meteorological variables (i.e. RH, WS, temperature, and atmospheric pressure) being 108 investigated. The objectives of this study were (1) to characterize the temporal variations of 109 visibility in the suburb of Ningbo; (2) to identify the relationships between classified visibility 110 and other parameters using multiple correspondence analysis (MCA); (3) to develop a regression 
111 model suitable for the prediction of visibility in Ningbo based on air pollutant data and

112 meteorological parameters.

\section{Material and Methods}

\subsection{Study Area and Data Source}

Eastern China. The climate conditions of Ningbo are governed by the sub-tropical monsoon, with prevailing northwest and southeast winds in winter and summer, respectively. The annual mean

120 air temperature and precipitation are $16.4^{\circ} \mathrm{C}$ and $1,480 \mathrm{~mm}$, respectively. Annual mean air 121 temperature reaches its maximum $\left(28.0^{\circ} \mathrm{C}\right)$ in July and minimum $\left(4.7^{\circ} \mathrm{C}\right)$ in January. During the 122 whole year, approximately $60 \%$ of the annual mean precipitation occurs from May to September.

123 The annual mean WS is $2-3 \mathrm{~m} / \mathrm{s}$ in urban areas and $>5 \mathrm{~m} / \mathrm{s}$ in coastal areas.

Air pollutant concentrations and meteorological data collected from June 1, 2013 to May 31, 2015 at the Dongqian Lake (DQL) Monitoring Station $\left(29^{\circ} 45^{\prime} \mathrm{N}, 121^{\circ} 37^{\prime} \mathrm{E}\right)$ were used in this study. The monitoring station is $12 \mathrm{~km}$ away from the city center of Ningbo and $1.3 \mathrm{~km}$ from the biggest freshwater lake (Dongqian Lake, $22 \mathrm{~km}^{2}$ in area) in the Zhejiang Province. There are several hills nearby to the west and east. Many small villages are distributed at the mountain foot

129 less than $2 \mathrm{~km}$ to DQL site. There is a provincial road close to this site with small factories

130 involved in mechanical processing built alongside. In recent years, the tourism resources around 131 DQL have been greatly developed, with increasing numbers of urban residents visiting the area 132 for recreational purposes.

133 The DQL station is a part of the national air quality monitoring network of China, which is 134 under the supervision of the national Ministry of Environmental Protection (MEP). Visibility is 135 measured by trained operators using easily identifiable structures and objects, such as tall 136 buildings, towers, and mountain ridges, at predetermined distances. The routine monitoring of air 
137 quality with six conventional indices (i.e. $\mathrm{SO}_{2}, \mathrm{CO}, \mathrm{NO}_{2}, \mathrm{O}_{3}, \mathrm{PM}_{10}, \mathrm{PM}_{2.5}$ ) at DQL station began 138 in 2012 when the latest ambient air quality standards of China (GB 3095-2012) were established.

139 Commercial instruments from Thermo-Fisher Scientific Inc. (USA) are used to measure gaseous 140 pollutants, such as $\mathrm{O}_{3}$ (Model 49i), $\mathrm{NO}_{2}$ (Model 42i), $\mathrm{CO}$ (Model 48i) and $\mathrm{SO}_{2}$ (Model 43i). $141 \mathrm{PM}_{2.5}$ and $\mathrm{PM}_{10}$ are measured using a tapered-element oscillating microbalance sampler (R\&P 142 TEOM, 1400). The TEOM sampler is calibrated regularly by using filters with measured masses. 143 Zero and span checks are made weekly. Hourly averaged data were used for all analyses in this 144 study and described by local time $(\mathrm{UTC}+8)$. Meteorological variables including RH, WS, 145 temperature, and atmospheric pressure are measured by automatic weather station (WS500-UMB, 146 Lufft, Germany) at DQL site. The fire count map was retrieved from FIRMS Web Fire Mapper 147 (NASA, https://earthdata.nasa.gov/).

148 The Air Quality Index (AQI) has been developed to provide daily air quality information to 149 the public in China (Zheng et al., 2014). On February 29, 2012, the Ministry of Environmental 150 Protection (MEP) of the People's Republic of China (PRC) approved the technical regulation on 151 ambient air quality index (GB 3095-2012), which released $\mathrm{PM}_{2.5}$ values and calculated the AQI 152 instead of the Air pollution Index (API). A sub-index is calculated for each pollutant from a 153 segmented linear function that transforms ambient concentrations onto a scale from 0 to 500 . AQI 154 is calculated as the sub-index maximum (China's Environmental Protection Standards, HJ 633155 2012). Daily AQI is defined as:

$156 \mathrm{AQI}=\max \left(\mathrm{AQI}_{P M_{10}}, \mathrm{AQI}_{P_{2}, 5}, \mathrm{AQI}_{\mathrm{SO}_{2}}, \mathrm{AQI}_{\mathrm{NO}_{2}}, \mathrm{AQI}_{\mathrm{CO}}, \mathrm{AQI}_{O_{3}}\right)$

157 where $\mathrm{AQI}_{P_{10}}, \mathrm{AQI}_{P_{2}, 5}, \mathrm{AQI}_{\mathrm{SO}_{2}}, \mathrm{AQI}_{\mathrm{NO}_{2}}, \mathrm{AQI}_{C O}$ and $\mathrm{AQI} \mathrm{O}_{3}$ are the partial index of air pollutants $158 \quad \mathrm{PM}_{10}, \mathrm{PM}_{2.5}, \mathrm{SO}_{2}, \mathrm{NO}_{2}, \mathrm{CO}$ and $\mathrm{O}_{3}$, respectively.

$159 \mathrm{AQI}_{p}=\left[\left(\mathrm{AQI}_{p h}-\mathrm{AQI}_{p l}\right) /\left(\mathrm{C}_{\text {high }}-\mathrm{C}_{\text {low }}\right)\right] \times\left(\mathrm{C}_{p}-\mathrm{C}_{\text {low }}\right)+\mathrm{AQI}_{p l}$ 
160 where $\mathrm{AQI}_{p}$ is the partial index of air pollutant $p, \mathrm{C}_{p}$ is the daily average concentration of air

161 pollutant $p, \mathrm{C}_{\text {high }}$ and $\mathrm{C}_{\text {low }}$ are the threshold concentrations of $p$ at air quality grade, respectively.

162 Corresponding to $\mathrm{C}_{\text {high }}$ and $\mathrm{C}_{\text {low }}, \mathrm{AQI}_{p h}$ and $\mathrm{AQI}_{p l}$ are the threshold partial indexes of air pollutant $163 p$ at air quality grade, respectively.

164

165

166

167 2010).

\subsection{Data Analysis}

Multiple correspondence analysis (MCA) is a data analysis technique for categorical data, used to detect and represent the underlying relationships in a data set. It is complementary to analytical models as the reduction and display of contingency tables produces graphics, which could depict the structural relationships among categories within variables (Hair et al. 1995; Hill et al. 2007). The purpose of MCA, also known as homogeneity analysis, is to find quantifications that are optimal in the sense that the separation of categories is maximised. This implies that objects in the same category are plotted close to each other and objects in different categories are plotted as far apart as possible. The analysis is most successful when the variables are homogeneous; that is, when they partition objects into clusters with the same or similar categories. This statistical method has been widely used in sociology, economic statistics, medical science, but is still limited in environmental science (Van Stan et al. 2016; Sourial et al.

\section{Results and Discussion}

\subsection{Overall Results of the Study Area}

The overall statistical analysis of daily visibility, air pollutants, and meteorological variables during the two years of observations at DQL station are summarized in Table S1. Day-to-day variations of visibility, $\mathrm{PM}_{2.5}$ and $\mathrm{PM}_{10}$ are shown in Fig. S1. From June 1, 2013 to May 31, 2015 , the daily average visibility ranged from $0.6-34.1 \mathrm{~km}$, with a mean value of $11.8 \mathrm{~km}$, which 
186

187

was just over the defined threshold for haze (i.e. visibility $<10.0 \mathrm{~km}$ ), indicating poor air quality over the study region. The mean $\mathrm{PM}_{2.5}, \mathrm{PM}_{10}, \mathrm{SO}_{2}, \mathrm{NO}_{2}, \mathrm{CO}$ and $\mathrm{O}_{3}$ concentrations were 42.6 $\mu \mathrm{g} / \mathrm{m}^{3}, 64.6 \mu \mathrm{g} / \mathrm{m}^{3}, 15.0 \mu \mathrm{g} / \mathrm{m}^{3}, 28.9 \mu \mathrm{g} / \mathrm{m}^{3}, 0.9 \mathrm{mg} / \mathrm{m}^{3}$ and $70.2 \mu \mathrm{g} / \mathrm{m}^{3}$, respectively. The average value of AQI, RH, temperature, WS and surface pressure were $65.6,73.2 \%, 17.8^{\circ} \mathrm{C}, 1.7 \mathrm{~m} / \mathrm{s}$ and 1013.0 hPa, respectively.

Visibility impairment mainly resulted from airborne particulate matter, particularly from fine particles with aerodynamic diameters less than $2.5 \mu \mathrm{m}$ (Deng et al. 2014; Sabetghadam and Ahmadi-Givi 2014). According to air quality daily report from MEP, $\mathrm{PM}_{2.5}$ in the atmosphere was the primary pollutant of concern in Ningbo during the two years (http://www.zhb.gov.cn). Therefore, the daily variations of $\mathrm{PM}_{10}$ and $\mathrm{PM}_{2.5}$ were required for analysis during the study period in DQL station. Fig. S1 shows that the concentrations of $\mathrm{PM}_{2.5}$ and $\mathrm{PM}_{10}$ were generally higher in winter and lower in summer, and the proportion of $\mathrm{PM}_{2.5}$ in $\mathrm{PM}_{10}$ was relatively high. During the two years, almost all daily $\mathrm{PM}_{2.5}$ concentrations in winter exceeded the national ambient air quality standard Grade II $\left(75 \mu \mathrm{g} / \mathrm{m}^{3}\right)$, revealing severe pollution from fine particles. In December, 2013, extremely high levels of $\mathrm{PM}_{10}$ and $\mathrm{PM}_{2.5}$ were observed with daily average concentrations of 511 and $389 \mu \mathrm{g} / \mathrm{m}^{3}$, respectively. At 22:00 on December 6 , the hourly concentrations of $\mathrm{PM}_{10}$ and $\mathrm{PM}_{2.5}$ reached peak values of 707 and $530 \mu \mathrm{g} / \mathrm{m}^{3}$, respectively. Visibility dramatically decreased to $0.6 \mathrm{~km}$ during this episode, which was the minimum value measured during the two years. This haze episode was also observed by Xue et al. (2015) in the YRD region.

\subsection{Seasonal and Diurnal Variation of Visibility}

Fig. 1(a) shows that $43.4 \%$ of the daily visibility was less than $10.0 \mathrm{~km}$ during the two years and only $9.2 \%$ was greater than $20.0 \mathrm{~km}$, indicating bad air quality in DQL area. The maximal frequency $(33.4 \%)$ of daily visibility was observed in the range of $5.0-10.0 \mathrm{~km}$. Poor visibility 
$211(<5.0 \mathrm{~km})$ often occurred in winter with a frequency of 53.4\%. Daily visibilities of spring and

212 summer contributed as much as $41.8 \%$ and $38.8 \%$ to the visual range of $20.0-35.0 \mathrm{~km}$, 213 respectively.

214 Generally, the average value of AQI decreased with increasing visibility (Fig. 1). The mean 215 value of AQI for the visual range of $0-5.0 \mathrm{~km}$ was $111.8(\geq 100)$, which indicates the occurrence 216 of a haze episode under low visibility. The AQI values were 72.3 and 61.4 for the visual range of $217 \quad 5.0-10.0 \mathrm{~km}$ and $10.0-15.0 \mathrm{~km}$, respectively. This indicates that the local air was moderately 218 polluted. Good visibility $(15.0-35.0 \mathrm{~km})$ occurred simultaneously with the lowest AQI value $219(<50)$ i.e. when the air quality was good. These data confirm that the local air quality had an 220 obvious positive correlation with visibility (Tsai et al. 2003).

221 Fig. 1(b) depicts the diurnal patterns of annual and seasonal mean visibility in Ningbo. 222 Visibility shows an obvious and similar diurnal variation throughout four seasons, with a sharp 223 decrease in early morning, i.e. 06:00-08:00 local time and a peak in afternoon, i.e. 14:00-16:00 224 local time. From the perspective of the annual average, the lowest and highest visibility was 7.5 $225 \mathrm{~km}$ and $15.6 \mathrm{~km}$, respectively. The diurnal patterns during different seasons were desynchronized, 226 which is due to the difference in weather pattern (i.e. day-night length, sunrise and sunset time, 227 monsoon etc.) and the stability of atmospheric boundary layer (ABL) in each season. For 228 example, the trough and peak of visibility in wintertime are nearly two hours later than 229 summertime, which is mainly attributed to a later sunrise time and smaller ABL depth. It can also 230 be seen that visibility in spring and summer was better than autumn and winter, and winter is 231 more likely associated with poor visibility and bad air quality.

\subsection{Monthly Variations of Visibility and Environmental Factors}

Monthly variations of visibility, air pollutant concentrations and meteorological factors were

235 investigated in this study (Fig. 2). The highest average visibility was observed in July, with a 
236 value of $16.6 \mathrm{~km}$, and the lowest average visibility was observed in December with a value of 9.1

$237 \mathrm{~km}$. Different trends of monthly variations were observed between visibility and other

238 environmental variables in the study area (Fig. 2). It was noteworthy that the visibility greatly

239 decreased in June, when the air pollutant concentrations stayed at low levels. As is well known

240 that visibility is negatively correlated with air humidity (Deng et al., 2011). The relatively high

241 level of RH in June (Fig. 2) might account for the lower visibility due to the light scattering and

242 absorption of water vapour.

243 Fig. 2 shows that the $\mathrm{PM}_{10}$ and $\mathrm{PM}_{2.5}$ pollution of the study area was severe. The monthly

244 mass concentrations of $\mathrm{PM}_{10}$ and $\mathrm{PM}_{2.5}$ were in the range of 34.7-139.3 and 23.7-94.9 $\mu \mathrm{g} / \mathrm{m}^{3}$,

245 respectively. The concentrations of $\mathrm{PM}_{10}$ and $\mathrm{PM}_{2.5}$ were higher from November to February,

246 while lower from June to September. The temporal variations of anthropogenic emissions and

247 weather conditions might account for the seasonal cycle of PM. The average ratio of $\mathrm{PM}_{2.5}$ to

$248 \mathrm{PM}_{10}\left(\mathrm{PM}_{2.5} / \mathrm{PM}_{10}\right)$ was $66.6 \%$ with a range of $59.3 \%-72.1 \%$. Remarkably, there was an obvious

249 inverse correlation between visibility and the ratio of $\mathrm{PM}_{2.5} / \mathrm{PM}_{10}$, especially in June, July and

250 October. The high proportions of $\mathrm{PM}_{2.5}$ contained within $\mathrm{PM}_{10}$ in poor visibility episodes

251 indicated that fine particles could play an important role in affecting local visibility.

252 The monthly variations of $\mathrm{SO}_{2}, \mathrm{NO}_{2}$ and $\mathrm{CO}$ were consistent with that of PM, with higher and

253 lower concentrations being observed in winter and summer, respectively. All three gaseous

254 pollutants showed non-significant correlation with visibility. However, a strong correlation

255 between $\mathrm{O}_{3}$ and visibility was observed during the study period (Fig. 2). Two monthly peaks of

$256 \mathrm{O}_{3}$ were observed in May $\left(100.3 \mu \mathrm{g} / \mathrm{m}^{3}\right)$ and October $\left(71.4 \mu \mathrm{g} / \mathrm{m}^{3}\right)$ along with better visibility,

257 while the lowest $\mathrm{O}_{3}$ concentration $\left(41.4 \mu \mathrm{g} / \mathrm{m}^{3}\right)$ occurred in December when lower visibility was

258 observed. The winter minimum $\mathrm{O}_{3}$ level is commonly observed in mid-latitude locations in the

259 Northern Hemisphere (Tu et al. 2007; Semple et al. 2012; kumar et al. 2010), which is mainly 
260 due to the relatively weaker photochemical processes. Good visibility is often related to stronger

261 solar radiation, which can significantly promote the photochemical generation of $\mathrm{O}_{3}$ (Pudasainee

262 et al. 2006). This might account for the good correlation between $\mathrm{O}_{3}$ levels and visibility during

263 warm seasons in this study.

264 The variation of RH displayed a summer maximum and winter minimum, with the highest 265 (82.1\%) and lowest (62.3\%) values occurring in June and December, respectively. Clear positive 266 and negative correlations existed between $\mathrm{RH}$ and $\mathrm{PM}_{2.5} / \mathrm{PM}_{10}$, and between $\mathrm{RH}$ and visibility, 267 respectively. With the increase of $\mathrm{RH}$, the generation of secondary aerosols in fine particles was 268 enhanced and the hygroscopic components of aerosols such as sulfate, nitrate and sea salt 269 absorbed more moisture, which would increase the scattering cross section of the aerosols and 270 reduce visibility (Jung et al. 2009).

271 Obvious monthly variations of surface WS were observed in the study area, with the highest 272 value $(2.4 \mathrm{~m} / \mathrm{s})$ occurring in July and the lowest value $(1.4 \mathrm{~m} / \mathrm{s})$ occurring in November (Fig. 2). 273 Monthly visibility was positively correlated with WS during most months, especially in summer 274 (June-August) and autumn (September-November). Generally, the increase of WS accelerates the 275 diffusion of dust and pollutants, which leads to an increase of the visual range. Meanwhile, the 276 temperature and pressure also changed obviously in different months. Temperature was highest $277\left(29.5^{\circ} \mathrm{C}\right)$ in July and lowest $\left(7.0^{\circ} \mathrm{C}\right)$ in December, while the barometric pressure was highest $278(1025.9 \mathrm{hPa})$ in December and lowest $(1005.1 \mathrm{hPa})$ in July. In general, the variation of visibility 279 was consistent with that of temperature and opposite to that of pressure. The correlations between 280 visibility and temperature and pressure might be accounted for by the following reasons. High air 281 temperature and low pressure usually enhances the dispersal capability of the atmosphere via 282 thermal and mechanical turbulence, which could promote the improvement of air quality and 
283 visibility and inversely, low temperature and high pressure indicate more stable weather 284 condition, which would weaken the diffusion of air pollutants.

\subsection{Multiple Correspondence Analysis of Visibility}

In multiple correspondence analysis, all variables were divided into four categories according to the values from small to large (Table S2). In the following discussion, the Arabic 1 to 4 were used to represent the four categories respectively; the category indicator was added as a prefix for air pollution; and as a suffix for meteorological parameter. The correspondence map and loading

291 factors of visibility and other environmental variables based on MCA are shown in Fig. 3 and 292 Table S3, respectively. Most of the variance in our data was accounted for in the analysis with 293 axes 1 and 2 explaining 41.5\% and 25.4\% variation, respectively. Almost all air pollutants and 294 meteorological factors were classified into four quadrants in the map. The relative distance between variables and the closeness of points on the map with respect to their angle from the origin, and points in the same quadrant can be used to interpret relationships between variables

297 (Higgs et al. 1991; Garson et al. 2012). The origin on the map corresponds to the centroid of each 298 variable. The closer a variable is to the origin, the closer it is to the average profile. As shown in 299 Fig. 3, V2 and V3 was near the origin and was the primary visual range during the study period, as described above. During the study period, the frequency of daily visibility appearing in the

301 range of 5.0-15.0 km was higher than those of others (Fig. 1). In addition, $4 \mathrm{NO}_{2}, 4 \mathrm{CO}$ and $4 \mathrm{SO}_{2}$ 302 were located far from the origin in the first quadrant and therefore had the greater variability. This 303 implied that the concentration of air pollutants were inclined to have the greatest effect compared 304 to other factors during the poor visual range $(\mathrm{V} 1<5 \mathrm{~km})$. Along dimension 2 , it was observed that $305 \mathrm{~T} 4,1 \mathrm{PM}_{2.5}, 1 \mathrm{CO}$ and WS4 had the most effect, indicating that the lower concentrations of 306 pollutants except for $\mathrm{O}_{3}$, higher temperature and higher wind speed had a significant influence on 307 good visibility (V4 $>15 \mathrm{~km})$. 
Fig. 3 illustrates that the first two dimensions accounted for $66.9 \%$ of the total variance and

309 the majority of variables were clearly discriminated in both dimensions. Along dimension 1,

310 values of $\mathrm{PM}_{2.5}, \mathrm{SO}_{2}, \mathrm{CO}, \mathrm{NO}_{2}$ and $\mathrm{P}$ increased positively with the direction of dimension 1.

311 Conversely, T, V and WS decreased in dimension 1. However, only WS along dimension 2

312 changed regularly, which increased in a positive direction. Generally, dimension 1 could account

313 for most air pollutants, P, T, V and WS; and dimension 2 only explained WS additionally.

314 However, the two dimensions in our study could not well represent the variations of $\mathrm{O}_{3}$ and $\mathrm{RH}$,

315 and the lower loading factors of $\mathrm{O}_{3}$ and $\mathrm{RH}$ in Table $\mathrm{S} 3$ also confirmed this.

316 The variation of $\mathrm{O}_{3}$ concentrations and $\mathrm{RH}$ did not regularly change with dimension 1 or 2 ,

317 indicating that further dimensions may need to be analysed, i.e. the variation of $\mathrm{O}_{3}$ has unique

318 characteristics. As previously discussed, visibility was usually positively related with $\mathrm{O}_{3}$

319 concentrations. $4 \mathrm{O}_{3}$ was closely distributed with $\mathrm{V} 3$ rather than $\mathrm{V} 4$ in the correspondence map

320 (Fig. 3), but the concentration of $\mathrm{O}_{3}$ did not increase with visibility completely. In fact, except for

321 the lower concentrations of $\mathrm{O}_{3}$, the points of $2 \mathrm{O}_{3}$ to $4 \mathrm{O}_{3}$ were all closely placed within the third

322 quadrants of Fig. 3, which were generally associated with a relatively higher temperature and

323 lower WS. The relatively high WS (WS4 \& WS3) in the second quadrant was unfavourable to the 324 accumulation of $\mathrm{O}_{3}$. These data also indicated that the production of $\mathrm{O}_{3}$ was not only affected by 325 visibility, other pollutants and meteorological parameters, but also factors including solar 326 radiation, which was not included in this study (Tong et al., 2017). In addition, the effects of RH 327 on visibility could not be ignored. The visibility was always below $15 \mathrm{~km}(\mathrm{~V} 1 \sim \mathrm{V} 3)$ when $\mathrm{RH}$ 328 was higher than $80 \%$ (i.e. RH3 \& RH4), which indicated that visibility remained at low values 329 even with low air pollution concentrations. 
332 To gain a deeper insight into how relevant factors affect visibility, Pearson correlations were 333 performed between daily visibility, air pollutants and meteorological variables (Table S4). 334 Visibility had significantly negative correlations with $\mathrm{PM}_{2.5}(\mathrm{r}=-0.50), \mathrm{CO}(\mathrm{r}=-0.51)$, and $\mathrm{NO}_{2}$ $335(\mathrm{r}=-0.47)$. The moderate relationship between visibility and $\mathrm{PM}_{2.5}$ was expected, given the 336 scattering effect of aerosols, especially fine aerosols with aerodynamic diameters of $2.5 \mu \mathrm{m}$ or less 337 (Charlson et al. 1992; $\mathrm{Xu}$ et al. 2002). Visibility had no direct relationship with CO, but the 338 correlation coefficient between both variables was a little higher than that between visibility and $339 \mathrm{PM}_{2.5}$. This may be because $\mathrm{CO}$ is generated by intensive biomass burning together with 340 incomplete combustion from vehicle engines, during which large quantities of particles would be 341 generated. Fine particles formed simultaneously with CO could lead to visibility reduction by 342 scattering and absorbing light radiation (Xue et al. 2015), which might account for the negative 343 correlation between visibility and $\mathrm{CO}$. For $\mathrm{NO}_{2}$, there was a weak direct influence on visibility. 344 However, secondary pollutants such as nitrate, which is produced by photochemical conversions 345 from $\mathrm{NO}_{2}$ might play an important role in visibility reduction (Sabetghadam and Ahmadi-Givi 346 2014). Nitrate is the main water-soluble constituent in $\mathrm{PM}_{2.5}$ and is an important factor in the 347 increase of $\mathrm{PM}_{2.5}$ concentrations. A strong positive correlation between $\mathrm{NO}_{2}$ and $\mathrm{PM}_{2.5}(r=0.70$, 348 Table S4) was observed in this study, which might explain why $\mathrm{NO}_{2}$ was significantly correlated 349 with visibility in the DQL area.

350 In analyses examining effects of meteorological factors, visibility showed a significant 351 positive correlation $(r=0.39)$ with WS and negative correlation $(r=-0.40)$ with $\mathrm{RH}$, which was 352 in accordance with previous research (Deng et al. 2011; Zhang et al. 2015). High wind speed 353 would promote the dispersion of pollutants and could reduce air pollutant concentrations and 354 increase visibility. Also, hygroscopic aerosols are greatly increased with high RH, which could 355 cause the increase of PM concentration and extinction capability, further reducing visibility. As 
presented in Table S4, visibility showed a rather weak negative and positive correlation with air

357 pressure and temperature, respectively. Air pressure and temperature are both important 358 indicators of weather system at a given location, and they have no direct effect on visibility. The 359 changes of air pressure and temperature could have an impact on the diffusivity of atmosphere, 360 and further affect the concentration of air pollutants. The relatively high correlation between $361 \mathrm{PM}_{2.5}$ and temperature $(r=-0.45)$, and between $\mathrm{PM}_{2.5}$ and pressure $(r=0.43)$ also confirmed this 362 conclusion.

363 Scatter plots and regression functions of one-year data (Fig. 4) were applied in this study in 364 order to examine the deep connections between visibility and the two major factors (i.e. $\mathrm{PM}_{2.5}$ 365 and RH). Fig. 4 and obtained equation (3) show the relationships between hourly-averaged 366 visibility and mass concentration of $\mathrm{PM}_{2.5}$ under different $\mathrm{RH}$ conditions (Yu et al., 2016). $\mathrm{RH}$ 367 was classified over four ranges: $\mathrm{RH} \leq 60 \%, 60<\mathrm{RH} \leq 80 \%, 80<\mathrm{RH} \leq 90 \%$, and $\mathrm{RH}>90 \%$. The 368 visibility decreased exponentially with increasing $\mathrm{PM}_{2.5}$ concentrations in each $\mathrm{RH}$ range.

Visibility $=f\left(\mathrm{PM}_{2.5}\right)=\left\{\begin{array}{cc}35.65 \times \exp \left(-0.017 \times \mathrm{PM}^{2.5}\right), \quad(\mathrm{RH} \leq 60 \%), \mathrm{r}=0.835 \\ 28.99 \times \exp \left(-0.020 \times \mathrm{PM}^{2.5}\right), & (60 \%<\mathrm{RH} \leq 80 \%), \mathrm{r}=0.732 \\ 22.84 \times \exp \left(-0.027 \times \mathrm{PM}^{2.5}\right), & (80 \%<\mathrm{RH} \leq 90 \%), \mathrm{r}=0.599 \\ 9.32 \times \exp \left(-0.021 \times \mathrm{PM}^{2.5}\right), & (\mathrm{RH}>90 \%), \mathrm{r}=0.384\end{array}\right.$

Firstly, with the increase of $\mathrm{PM}_{2.5}$ concentration, the visual range decreased exponentially. 371 Initially, the visibility decreased sharply while the $\mathrm{PM}_{2.5}$ concentration increased; but when $\mathrm{PM}_{2.5}$ 372 concentrations reached a certain level (for example above $100 \mu \mathrm{g} / \mathrm{m}^{3}$ ), the change in visibility was 373 not sensitive to $\mathrm{PM}_{2.5}$ concentrations any further. Secondly, with the increase of $\mathrm{RH}$, a lower 374 correlation coefficient between $\mathrm{PM}_{2.5}$ and visibility was observed. This implied that visibility 375 stayed at a very low level when $\mathrm{RH}$ values were very high $(>80 \%)$, even with low $\mathrm{PM}_{2.5}$ 376 concentrations. In this case, a large amount of water vapour could cover particle surfaces, 377 enhancing the scattering ability of aerosol and reduce visibility significantly. Thirdly, the 
maximum visibility under different RH conditions was decreased with the increase of RH value

379 (Fig. 4). Equation (3) suggested that the maximum visibility was just $9.32 \mathrm{~km}$ in the case of RH $380>90 \%$, and this result was consistent with MCA (Fig. 3).

381 Obviously, a single parameter regression as the equation (3) are not suitable for the 382 forecasting of visibility at another location or in another year, which ignores the effects of other 383 environmental variables, such as $\mathrm{NO}_{2}, \mathrm{CO}, \mathrm{T}$, WS etc. As presented in Fig. S2, in which a 384 separate year's hourly visibility was predicted with equation (3), the regression lines between 385 observed and simulated visibility significantly deviate from the 1:1 diagonal line. A larger 386 deviation existed when $\mathrm{RH}>90 \%$, indicating a greater contribution of other factors to visibility. 387 Nevertheless, the above equation further confirmed the exponential relationship between 388 visibility and $\mathrm{PM}_{2.5}$ under different $\mathrm{RH}$ level. This finding should be the basis of a forecasting 389 model of visibility.

\subsection{Regression Model Development and Validation}

392 To further develop a brief model for visibility prediction in Ningbo, it was first assumed that 393 the apparent visibility is the final result of a combination of factors influencing air pollution 394 together with meteorological parameters. As shown in Equation (4),

$$
\text { Visibility }=f\left(P M_{2.5}\right)+f\left(R H, T, N_{2}, O_{3} \cdots\right)=f\left(P M_{2.5}\right)+\sum_{i}\left(a_{i} \cdot x_{i}\right)+\varepsilon
$$

396 where $x_{i}$ represents any important factor for visibility, $a_{i}$ is a linear regression coefficient, and $\varepsilon$ is 397 the error term.

$398 \quad$ Visibility $-f\left(P M_{2.5}\right)=\sum_{\mathrm{i}}\left(\mathrm{a}_{i} \cdot x_{i}\right)+\varepsilon$

399 or

$400 \quad$ Visibility $-\sum_{\mathrm{i}}\left(\mathrm{a}_{i} \cdot x_{i}\right)=f\left(P M_{2.5}\right)+\varepsilon$ 
The obtained regression parameters in equation (3) were chosen as initial values of modelling

402 fit. Multiple linear regression was conducted between the residue of prediction and other 403 environmental parameters. Datasets with hourly resolution from June 2014 to May 2015 were 404 used to develop the multiple nonlinear regression equations. An independent variable was added 405 into the regression equation by a stepwise procedure based on importance. It demonstrated that 406 for the first two $\mathrm{RH}$ categories, i.e. $\mathrm{RH} \leq 80 \%, \mathrm{RH}$ is the common factor in addition to particle 407 concentration for the variation of visibility, then the regression equations for these two levels 408 were eventually combined together. After several circles of regression and iteration, the final 409 modelling results considering main influencing factors besides $\mathrm{PM}_{2.5}$ and $\mathrm{RH}$ within three $\mathrm{RH}$ 410 ranges were listed in Table 1. It showed that the main contributors to visibility under different $411 \mathrm{RH}$ are different, and the influence of all variables on visibility was additive. Specifically, the 412 independent variables in the model are $\mathrm{PM}_{2.5}$, and $\mathrm{RH}$ when $\mathrm{RH} \leq 80 \%$, while $\mathrm{O}_{3}$ is the major 413 contributor to the visibility (aside from $\mathrm{PM}_{2.5}$ and $\mathrm{RH}$ ) within $\mathrm{RH}$ of $80-90 \%$. The importance of $414 \mathrm{O}_{3}$ in the model requires further investigation. Results presented in Table 1 also suggested 415 temperature can affect visibility when $\mathrm{RH}>90 \%$. Likely, temperature affects visibility by 416 influencing condensation of water vapour in the atmosphere.

417 To further verify the validity of the non-linear models combining exponential and multiple 418 linear regressions, hourly observed visibility data from June 2013 to May 2014 were examined. 419 Fig. 5 presents the simulated results based on equations in Table 1 vs. the observed visibility. 420 The newly developed multiple nonlinear model improved the visibility prediction with generally 421 higher $\mathrm{R}$ values compared to those based on single parameter regression model (equation 3 ), 422 especially under high RH (>90\%) conditions (Fig. S2). Time series of daily observed visibility 423 and daily visibility simulated by nonlinear regression model from June 2013 to May 2014 was 424 plotted in Fig. 6. There was a high degree of consistency between model-fitted visibility and 
425 observed visibility, indicating that the newly developed model is a suitable and practical model

426 for simulating visibility based on air quality in DQL area.

427

428

429

430

431

432

433

\section{Conclusions}

Visibility, atmospheric pollutants and meteorological variables monitored in a suburban area (DQL) of Ningbo from June 1, 2013 to May 31, 2015 were analyzed in this study. The characteristics of visibility and its affecting factors were described in detail using multiple statistical methods. Based on these analyses, the following conclusions can be derived:

The temporal variation of visibility in DQL during the study period demonstrated notable regional characteristics. The seasonal pattern of visibility was characterized by higher levels in spring-summer and lower levels in autumn-winter. Nearly half of all measurements of visibility were lower than $10 \mathrm{~km}$, indicating poor air quality over the study region. Visibility displayed an obvious diurnal variation in each season, with the lowest and highest visibility being $7.5 \mathrm{~km}$ at approximately $06: 00$, and $15.6 \mathrm{~km}$ at approximately $14: 00$, respectively.

The results of multiple correspondence analysis (MCA) indicated that good visibility was always associated with good meteorological conditions and low levels air pollutants, except for $\mathrm{O}_{3}$. The results of MCA explained $66.9 \%$ necessity of the segmented studies of visibility. Based on the correlation analysis, $\mathrm{PM}_{2.5}$, WS and relative humidity were found to have significant impacts on visibility in Ningbo. Also, model equations between visibility, PM and RH were derived, with visibility decreasing exponentially with increasing $\mathrm{PM}_{2.5}$ concentrations in different RH ranges. Additionally, the non-linear models combining exponential and multiple linear regressions were developed to investigate the underlying relationships between visibility, air quality and meteorological conditions. The main factors which have the largest influences on visibility under different $\mathrm{RH}$ ranges are different. Based on comparative evaluation, the model prediction effect is regarded to be relatively good for this suburban area. 
This study demonstrated that the correlations between visibility and air pollutants/metrological parameters are relative consistent; and it is possible to predict the visibility based on air quality and weather conditions, although it was based on only two years of data collected from one research station. In order to gain a more accurate understanding of the relationships between visibility and other factors, and to modify the regression equations developed for these Ningbo 456 datasets, analyses on long term and multipoint data are necessary. In addition, the effects of largeand meso-scale phenomena on visibility warrants further study.

\section{Acknowledgments}

This work was supported by the National Natural Science Foundation of China (No. 31300435,

463 Science Foundation of Ningbo City (No. 2015A610247), and Knowledge Innovation Program of the Chinese Academy of Sciences (No. IUEQN-2012-03).

468 Cao, J.J., Wang, Q.Y., Chow, J.C., Watson, J.G., Tie, X.X., Shen, Z.X., Wang, P., An, Z.S., 469 2012. Impacts of aerosol compositions on visibility impairment in Xi'an, China. Atmos. $470 \quad$ Environ. 59, 559-566.

471 Chan, Y.C., Simpson, R.W., Mctainsh, G.H., Vowles, P.D., Cohen, D.D., Bailey, G.M., 1999. Source apportionment of visibility degradation problems in Brisbane (Australia) using the

474 Charlson, R.J.; Schwartz, S.E.; Hales, J.M.; Cess, D.; Coakley, J.A.; Hansen, J.E., 1992. Climate 475 forcing by anthropogenic aerosols. Science 255, 423-430.

476 Che, H.Z., Zhang, X.Y., Li, Y., Zhou, Z.J., Chen, Z.L., 2006. Relationship between horizontal 477 extinction coefficient and $\mathrm{PM}_{10}$ concentration in Xi'an, China, during 1980-2002. 478 Particuology 4, 327-329. 
479 Cheng, Z., Wang, S.X., Fu, X., Watson, J.G., Jiang, J., Fu, Q., Chen, C., Xu, B., Yu, J., Chow, 480 J.C., Hao, J.M., 2014. Impact of biomass burning on haze pollution in the Yangtze River Delta, China; a case study in summer 2011. Atmos. Chem. Phys. 14, 4573-4585.

China Meteorological Administration, 2011. Observation and forecasting levels of haze; QX/T, 113-2010.

Deng, J.J., Wang, T.J., Jiang, Z.Q., Xie, M., Zhang, R.J., Huang, X.X., Zhu, J.L., 2011. Characterization of visibility and its affecting factorsover Nanjing, China. Atmos. Res. 101, 681-691.

Deng, J.J., Xing, Z.Y., Zhuang B.L., Du, K., 2014. Comparative study on long-term visibility trend and its affecting factors on both sides of the Taiwan Strait. Atmos. Res. 143, 266-278.

Du, K., Mu, C., Deng, J.J., Yuan, F., 2013. Study on atmospheric visibility variations and the impacts of meteorological parameters using high temporal resolution data: an application of environmental internet of things in China. Int. J. Sust. Dev. World. 20, 238-247.

Garson, G.D., 2012. Correspondence analysis [Internet]. Statnotes: topics in multivariate analysis. Available athttp://www.statisticalassociates.com/correspondenceanalysis.htm

Hair, J.F., Anderson, R.E., Tatham, R.L., Black, W.C., 1995. Multivariate Data Analysis, fourth ed. Prentice Hall College Division 745 p.

He, T.F., Yang, Z.Y., Liu, T., Shen, Y.P., Fu, X.H., Qian, X.J., Zhang, Y.L., Wang, Y., Xu, Z.W., Zhu, S.K., Mao, C., Xu, G.Z., Tang, J.L., 2016. Ambient air pollution and years of life lost in Ningbo, China. Sci. Rep. 6.

Hill, T., Lewicki, P., 2007. Statistics: Methods and Applications. Statsoft, Tulsa 800 p.

Higgs NT., 1991. Practical and innovative uses of correspondence analysis. Statistician 40, 183194.

Horvath, H., 1995. Estimation of the average visibility in central Europe. Atmos. Environ. 29, 241-246.

Hua, Y., Chen, Z., Zhang, J.K., Wang, S.X., Jiang, J.K., Chen, D., Cai, S.Y., Fu, X., Fu, Q.Y., Chen, C.H., Xu, B.Y., Yu, J.Q., 2015. Characteristic and source apportionment of $\mathrm{PM}_{2.5}$ during a fall heavy haze episode in the Yangtze River Delta of China. Atmos. Environ. 123, $380-391$.

Jung, J., Lee, H., Kim, Y.J., Liu, X.G., Zhang, Y.H., Gu, J.W., Fan, S.J., 2009. Aerosol chemistry and the effect of aerosol water content on visibility impairment and radiative forcing in Guangzhou during the 2006 Pearl River Delta campaign. J. Environ. Manage. 90, 3231-3244. 
511 Kim, Y.J., Kim, K.W., Kim, S.D., Lee, B.K., Han, J.S., 2006. Fine particulate matter characteristics and its impact on visibility impairment at two urban sites in Korea: Seoul and Incheon. Atmos. Environ. 40, 593-605.

514 Kumar, R., Naja, M., Venkataramani, S., Wild, O., 2010. Variations in surface ozone at Nainital: 515 a high-altitude site in the central Himalayas. J. Geophys. Res.-Atmos. 115, 751-763.

516 Lin, M., Tao, J., Chan, C.Y., Cao, J.J., Zhang, Z.S., Zhu, L.H., Zhang, R.J., 2012. Regression

Pudasainee, D., Sapkota, B., Shrestha, M.L., Kaga, A., Kondo, A., Inoue, Y., 2006. Ground level ozone concentrations and its association with $\mathrm{NO}_{\mathrm{x}}$ and meteorological parameters in Kathmandu valley, Nepal. Atmos. Environ. 40, 8081-8087.

Semple, D., Song, F., Gao, Y., 2012. Seasonal characteristics of ambient nitrogenoxides and ground-level ozone in metropolitan northeastern New Jersey. Atmos. Pollut. Res. 3, 247-257.

Sabetghadam, S., Ahmadi-Givi, F., 2014. Relationship of extinction coefficient, air pollution, and meteorological parameters in an urban area during 2007-2009. Environ. Sci. Pollut. Res. 21, $538-547$.

Shen, Z.X., Cao, J.J., Zhang, L.M., Qian, Z., Huang, R.J., Liu, S.X., Zhao, Z.Z., Zhu, C.S., Lei, Y.L., Xu, H.M., Zheng, C.L., 2016. Retrieving historical ambient $\mathrm{PM}_{2.5}$ concentrations using existing visibility measurements in Xi'an, Northwest China. Atmos. Environ. 126, 15-20.

Sourial, N., Wolfson, C., Zhu, B., Quail, J., Fletcher, J., Bergman, H., 2010. Correspondence analysis is a useful tool to uncover the relationship among categorical variables. J. Clin. Epi. $63,638-646$.

Tan, J.H., Duan, J.C., Chen, D.H., Wang, X.H., Guo, S.J., Bi, X.H., Sheng, G.Y., He, K.B., Fu, J.M., 2009a. Chemical characteristics of haze during summer and winter in Guangzhou. Atmos. Res. 94, 238-245.

Tan, J.H., Duan, J.C., He, K.B., Ma, Y.L., Duan, F.K., Chen, Y., Fu, J.M., 2009b. Chemical characteristics of $\mathrm{PM}_{2.5}$ during a typical haze episode in Guangzhou. J. Environ. Sci. 21, 774781.

Tong, L., Zhang, H.L., Yu, J., He, M.M., Xu, N.B., Zhang, J.J., Qian, F.Z, Feng, J.Y., Xiao, H., 2017. Characteristics of surface ozone and nitrogen oxides at urban, suburban and rural sites in Ningbo, China. Atmos. Res. 187, 57-68. 
Tsai, Y.I., 2005. Atmospheric visibility trends in an urban area in Taiwan 1961-2003. Atmos. Environ. 39, 5555-5567.

Tsai, Y.I., Lin, Y.H., Lee, S.Z., 2003. Visibility variation with air qualities in the metropolitan area in southern Taiwan. Water Air Soil Pollut. 144, 19-40.

Tu, J., Xia, Z.G., Wang, H., Li,W., 2007. Temporal variations in surface ozone and its precursors and meteorological effects at an urban site in China. Atmos. Res. 85, 310-337.

Van Stan, J.T., Gay, T.E., Lewis, E.S., 2016. Use of multiple correspondence analysis (MCA) to identify interactive meteorological conditions affecting relative throughfall. J. Hydro. 533, $452-460$.

Wang, Y., Zhuang, G.S., Sun, Y.L., An, Z.S., 2006. The variation of characteristics and formation mechanisms of aerosols in dust, haze, and clear days in Beijing. Atmos. Environ. 40, 6579-6591.

Wark, K., Warner, C.F., Davis, W.T., 1998. Air pollution-its origin and control, 3rd edition, Addison-Wesley, MA, United States, 573 p.

Watson, J.G., 2002. Critical review discussion-visibility: Science and regulation. J. Air Waste Manag. 52, 973-999.

Wen, C.C., Yeh, H.H., 2010. Comparative influences of airborne pollutants and meteorological parameters on atmospheric visibility and turbidity. Atmos. Res. 96, 496-509.

Xu, J., Bergin, M.H., Yu, X., Zhao, J., Carrico, C.M., Baumann, K., 2002. Measurement of aerosol chemical, physical and radiative properties in the Yangtze delta region of China. Atmos. Environ. 36, 161-173.

Xue, D., Li, C.F., Liu, Q., 2015. Visibility characteristics and the impacts of air pollutants and meteorological conditions over Shanghai, China. Environ. Monit. Assess. 187, 363-373.

Yang, L.X., Wang, D.C., Chen, S.H., Wang, Z., Zhou, Y., Zhou, X.H., Wang, X.W., 2007. Influence of meteorological conditions and particulate matter on visual range impairment in Jinan, China. Sci. Total. Environ. 383, 164-173.

Yu, X.N., Ma, J., An, J.L., Yuan, L., Zhu, B., Liu, D.Y., Wang, J., Yang, Y., Cui, H.X., 2016. Impacts of meteorological condition and aerosol chemical compositions on visibility impairment in Nanjing, China. J. Clean. Prod. 131, 112-120.

Zhang, X.Y., Wang, Y.Q., Niu, T. Zhang, X.C., Gong, S.L., Zhang, Y.M., Sun, J.Y., 2012. Atmospheric aerosol compositions in China: spatial/temporal variability, chemical signature, 
573 regional haze distribution and comparisons with global aerosols. Atmos. Chem. Phys. 12, $574 \quad 779-799$.

575 Zhang, Q.H., Zhang, J.P., Xue, H.W., 2010. The challenge of improving visibility in Beijing. 576 Atmos. Chem. Phys. 10, 7821-7827.

577 Zhao, P.S., Zhang, X.L., Xu, X.F., Zhao, X.J., 2011. Long-term visibility trends and 578 characteristics in the region of Beijing, Tianjin, and Hebei, China. Atmos. Res. 101, 711-718. 579 
Table 1 Regression models of visibility under different RH in DQL, June 2014-May 2015.

\begin{tabular}{lllr}
\hline \multicolumn{1}{c}{ Stepwise regression model } & & \multicolumn{2}{c}{ correlation coefficient } \\
\hline $\mathrm{V}=23.044+27.853 * \exp \left(-0.04199 \mathrm{PM}_{2.5}\right)-0.196 \mathrm{RH}$ & $\mathrm{RH} \leq 80 \%$ & 0.816 & 4247 \\
$\mathrm{~V}=56.072+24.44 * \exp \left(-0.07128 \mathrm{PM}_{2.5}\right)-0.536 \mathrm{RH}-0.037 \mathrm{O}_{3}$ & $80<\mathrm{RH} \leq 90 \%$ & 0.671 & 2049 \\
$\mathrm{~V}=79.095+10.228 * \exp \left(-0.06571 \mathrm{PM}_{2.5}\right)-0.822 \mathrm{RH}+0.033 \mathrm{~T}$ & $\mathrm{RH}>90 \%$ & 0.589 & 1697 \\
\hline
\end{tabular}

583

584

585

586 


\section{List of fugures}
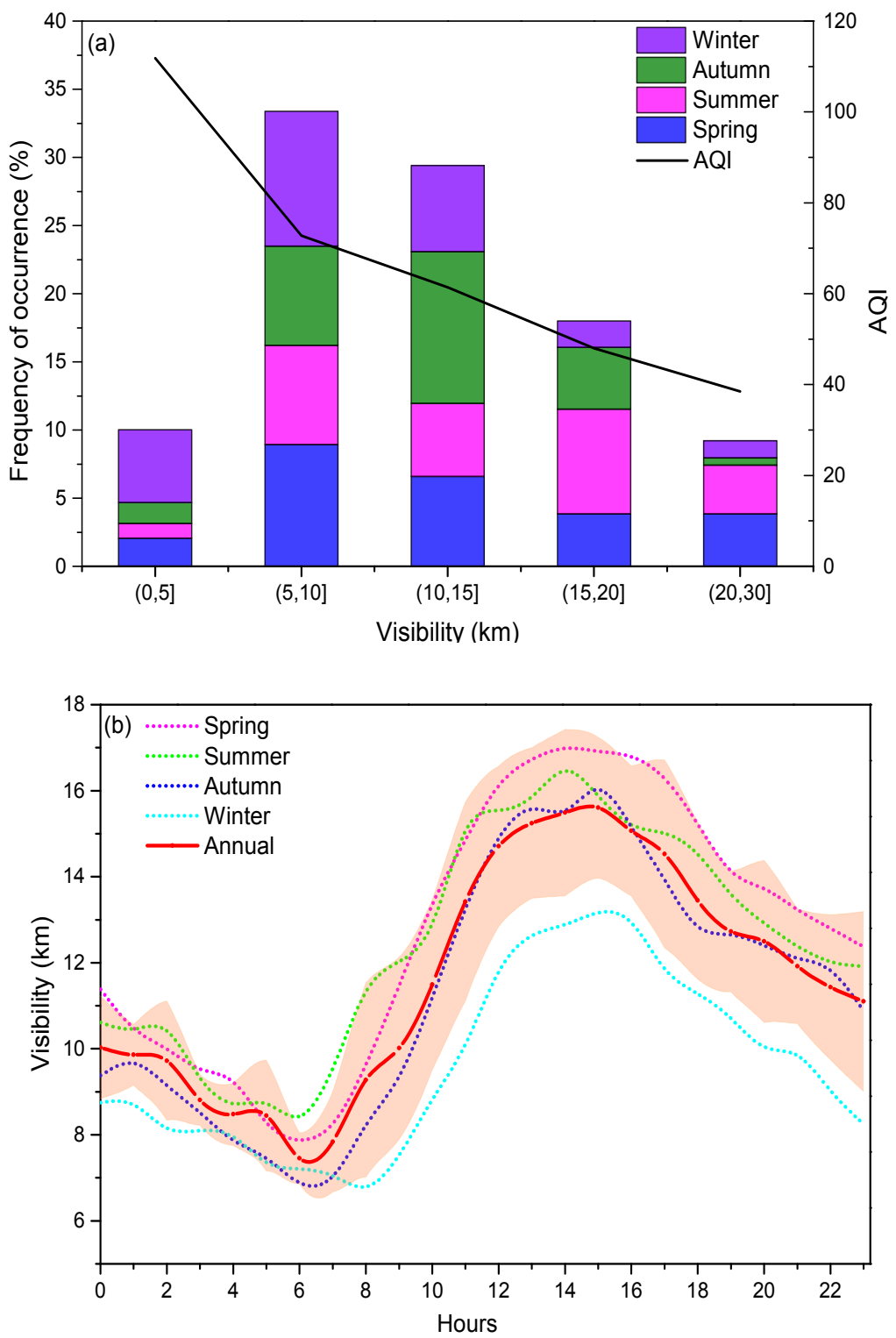

591 Fig. 1. Distribution of frequency of occurrence of daily visibility (a), and Diurnal variations of annual and seasonal visibility (b) at DQL in Ningbo. The shading area shows the standard deviations for the annual data. 


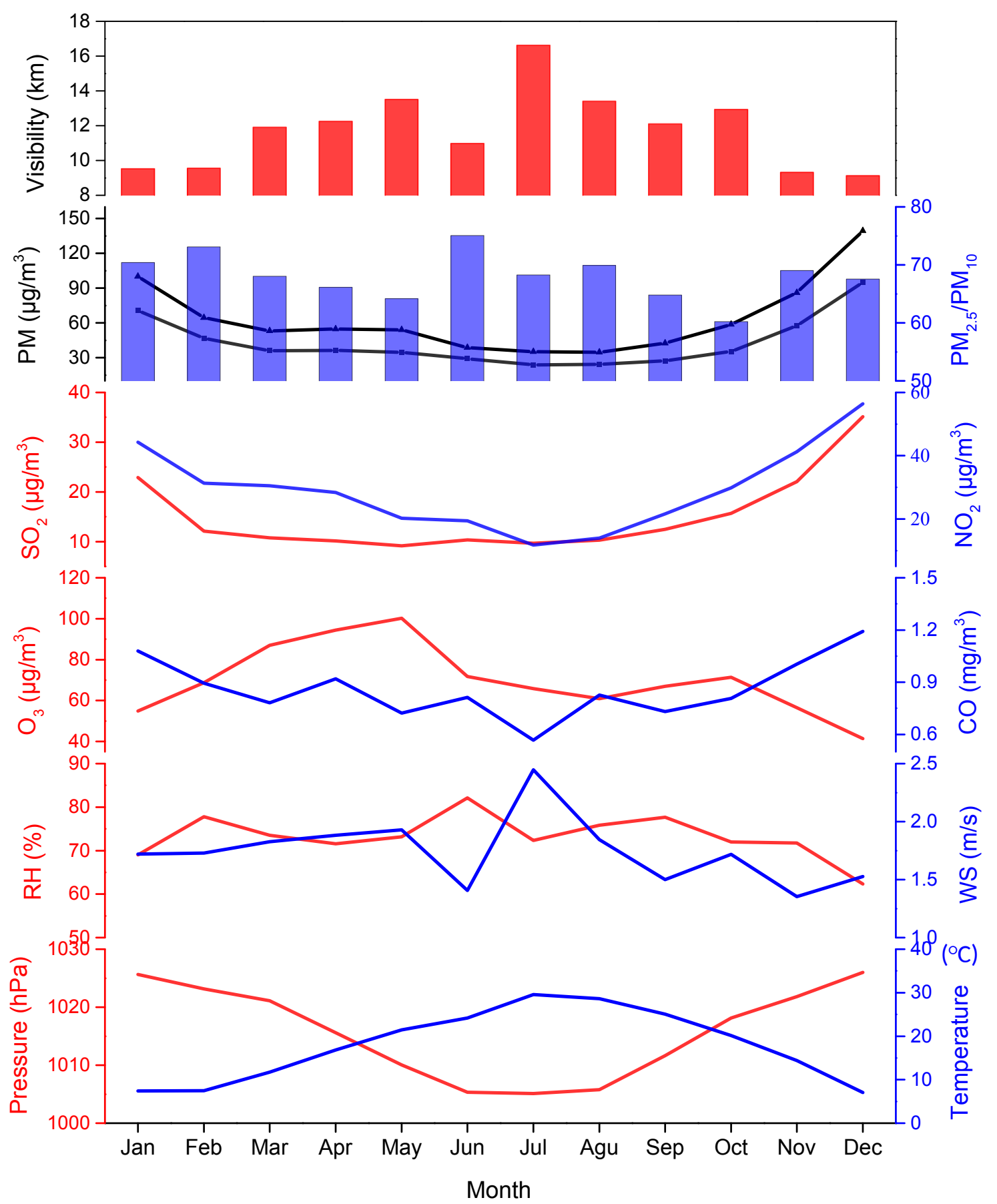

Fig. 2. Monthly variations of visibility and other environmental variables. 


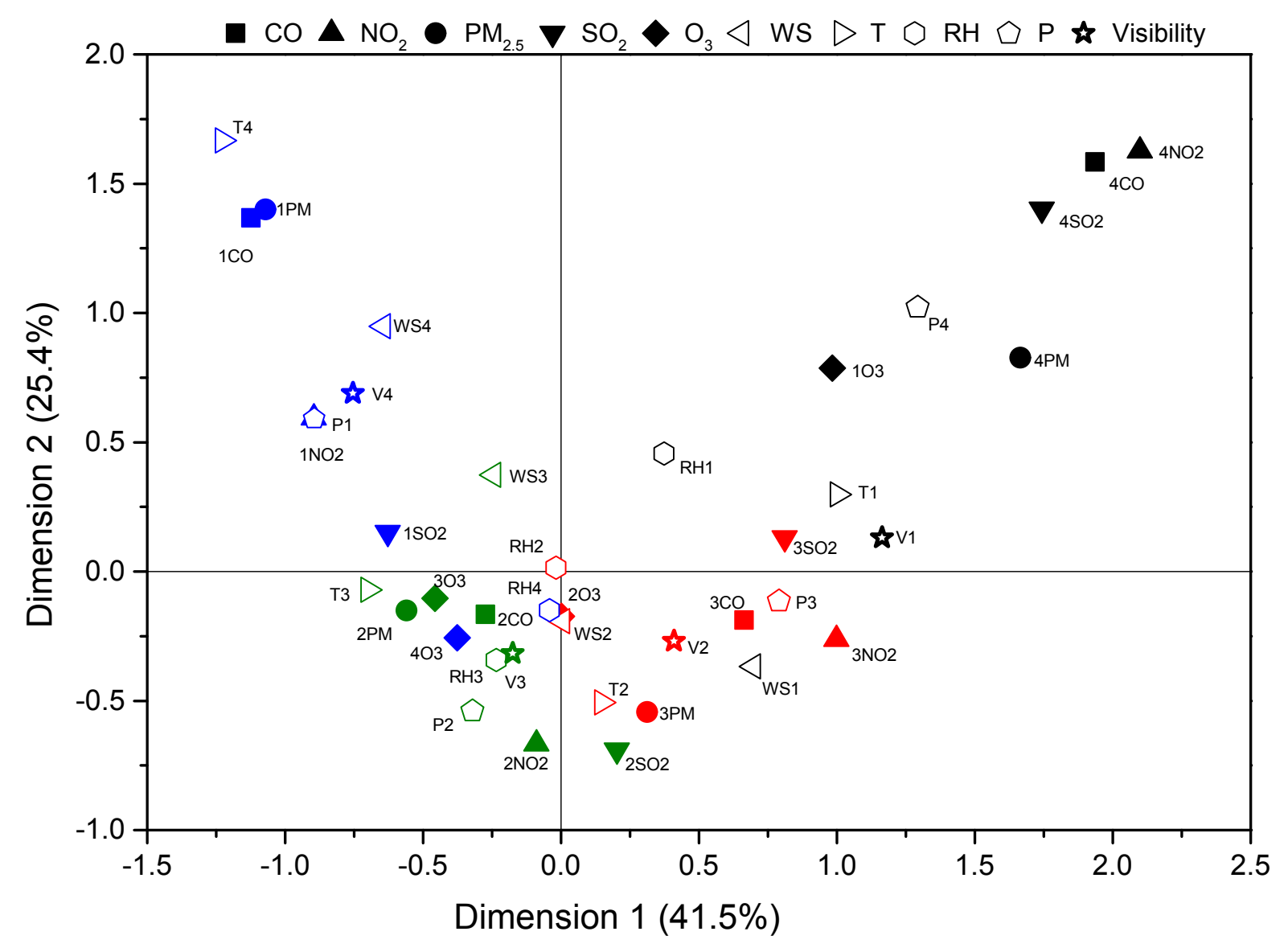

596

597 Fig. 3. Category quantification plot of classified visibility and other environmental variables at 598 DQL. 


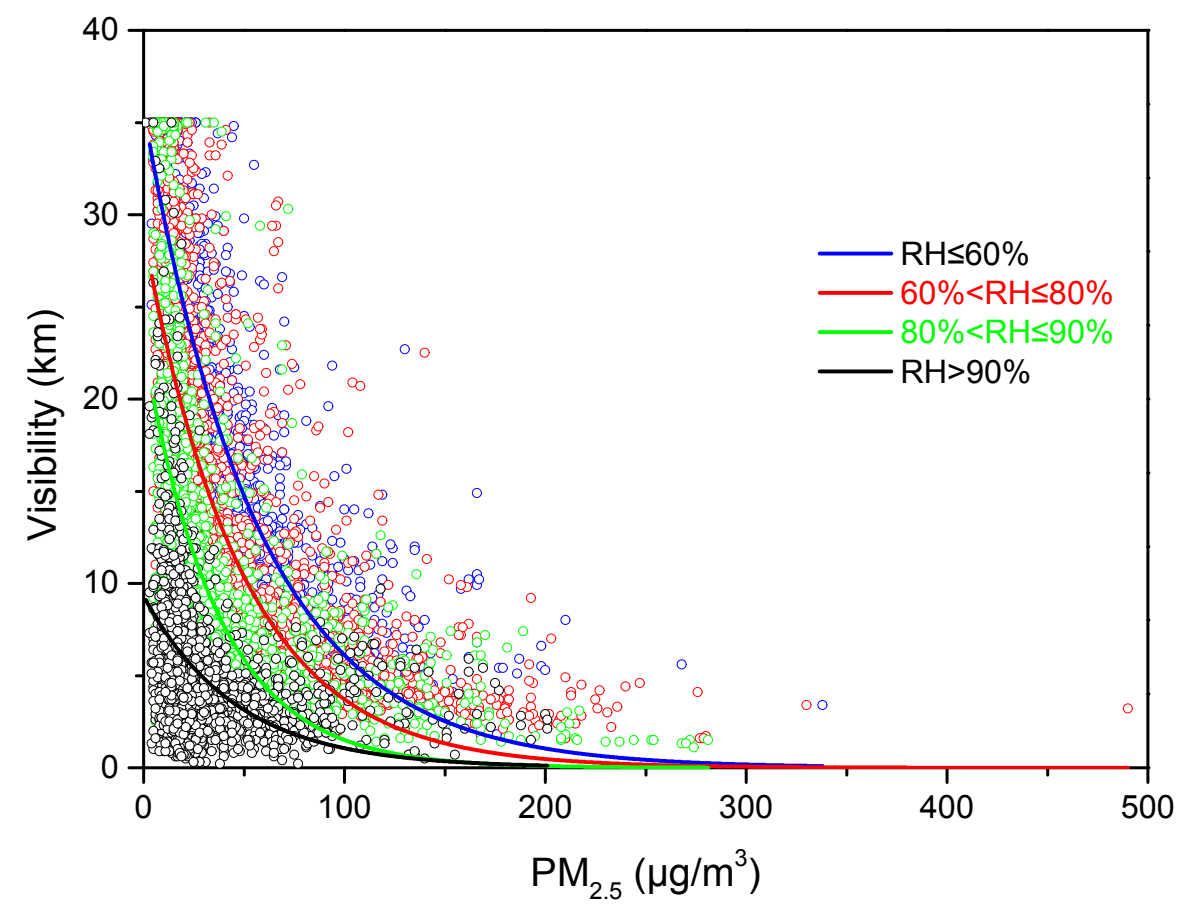

599

600 Fig. 4. Relationships between one-year visibility and $\mathrm{PM}_{2.5}$ at $\mathrm{DQL}$ (2014.6.1-2015.5.31). Data 601 points are color coded by RH. All the data are hourly average.
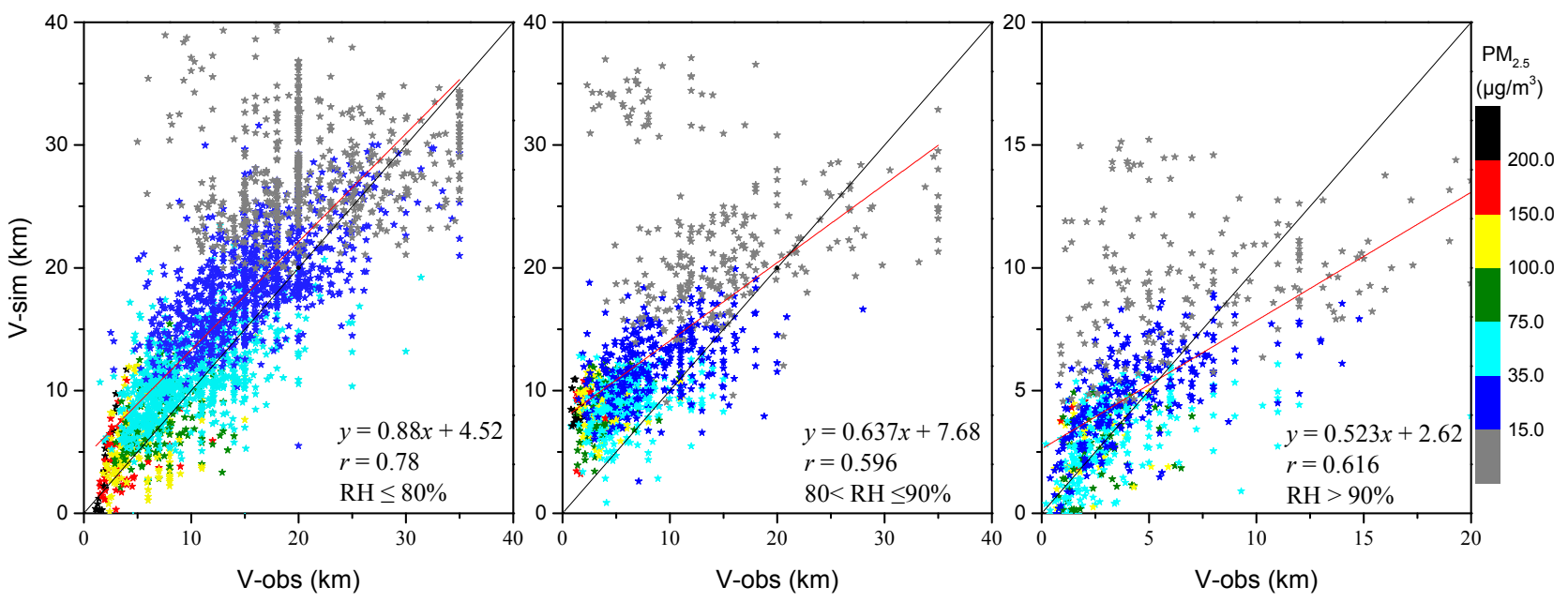

602

603 Fig. 5. Comparison between the observed hourly visibility and regression model simulated hourly 604 visibility during 2013.6-2014.5. (V-obs: the observed visibility; V-sim: the simulated visibility). 


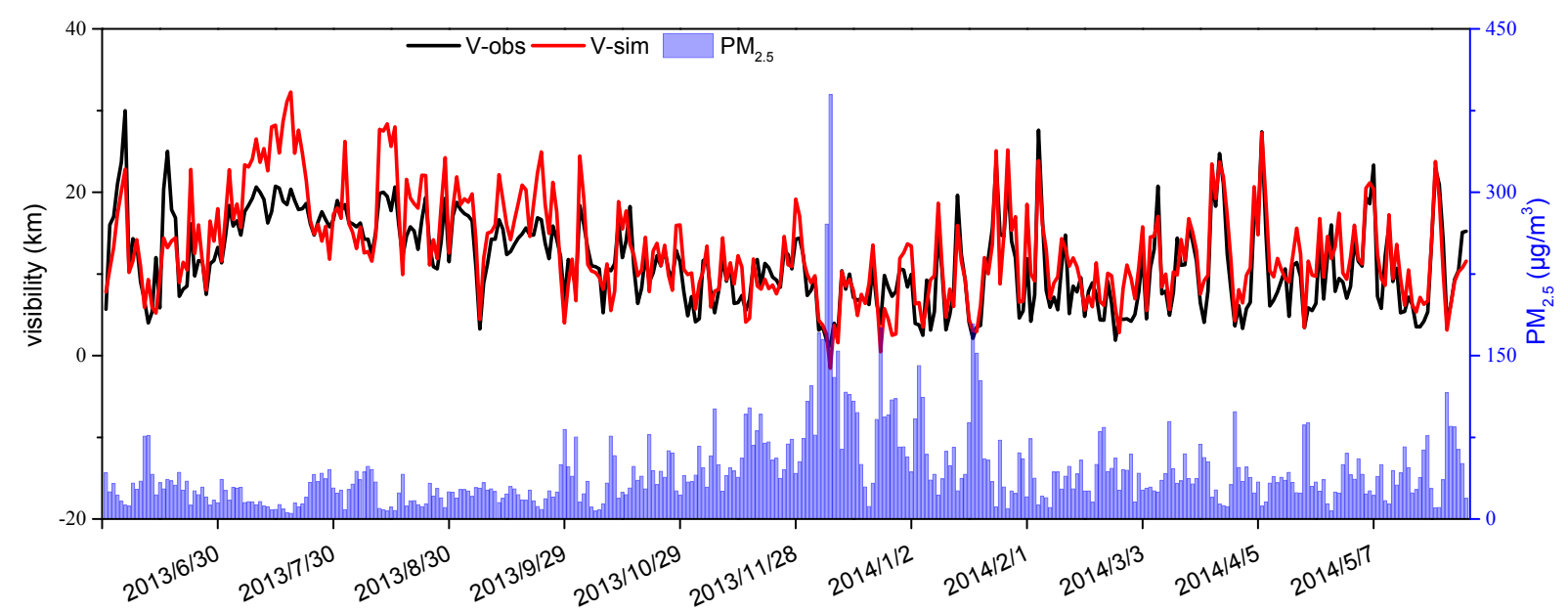

605

606

607

608
Fig. 6. Time series of daily observed visibility and daily simulated visibility by stepwise regression equations at DQL. (V-obs: the observed visibility; V-sim: the simulated visibility). 
609

610

611

612

613

614

615

616

617

618

619

620

621

622

623

624

625

626

627

628

629

630

631

632

633

634

635

636

637

638

639

640

641

642

643

644

645

\title{
Supporting Materials
}

\section{Temporal variability of visibility and its parameterizations in Ningbo, China}

\author{
Jingjing Zhanga, b, c, 1, Lei Tonga, b, 1, Chenghui Peng ${ }^{\mathrm{b}, \mathrm{c}}$, Huiling Zhang ${ }^{\mathrm{a}, \mathrm{c}}$, Zhongwen \\ Huang $^{\mathrm{a}, \mathrm{c}, \mathrm{d}}$, Jun He $\mathrm{H}^{\mathrm{e}}$, Hang Xiao ${ }^{\mathrm{a}, \mathrm{b}, *}$ \\ ${ }^{a}$ Center for Excellence in Regional Atmospheric Environment, Institute of Urban Environment, \\ Chinese Academy of Sciences, Xiamen 361021, China \\ ${ }^{b}$ Key Lab of Urban Environment and Health, Institute of Urban Environment, Chinese Academy \\ of Sciences, Xiamen 361021, China \\ ${ }^{c}$ University of Chinese Academy of Sciences, Beijing 100049, China \\ ${ }^{d}$ School of Chemistry and Environmental Engineering, Hanshan Normal University, Chaozhou, \\ 521041, China \\ e International Doctoral Innovation Centre, Department of Chemical and Environmental \\ Engineering, University of Nottingham Ningbo China, Ningbo, China
}


Table S1. Summary of visibility, AQI, and environmental factors from June, 2013 to May, 2015.

\begin{tabular}{lccccc}
\hline & Number & Min & Max & Mean & SD \\
\hline Visibility $(\mathrm{km})$ & 730 & 0.6 & 34.1 & 11.8 & 5.9 \\
$\mathrm{AQI}$ & 717 & 12.7 & 428.9 & 65.6 & 39.0 \\
$\mathrm{PM}_{2.5}\left(\mu \mathrm{g} / \mathrm{m}^{3}\right)$ & 717 & 5.3 & 389.8 & 42.6 & 33.4 \\
$\mathrm{PM}_{10}\left(\mu \mathrm{g} / \mathrm{m}^{3}\right)$ & 717 & 10.0 & 511.4 & 64.6 & 46.3 \\
$\mathrm{CO}\left(\mathrm{mg} / \mathrm{m}^{3}\right)$ & 717 & 0.1 & 2.6 & 0.9 & 0.3 \\
$\mathrm{NO}_{2}\left(\mu \mathrm{g} / \mathrm{m}^{3}\right)$ & 717 & 0.5 & 98.3 & 28.9 & 17.6 \\
$\mathrm{SO}_{2}\left(\mu \mathrm{g} / \mathrm{m}^{3}\right)$ & 717 & 2.0 & 76.2 & 15.0 & 12.3 \\
$\mathrm{O}_{3}\left(\mu \mathrm{g} / \mathrm{m}^{3}\right)$ & 717 & 5.3 & 184.9 & 70.2 & 29.9 \\
$\mathrm{Temperature}\left({ }^{\circ} \mathrm{C}\right)$ & 730 & 0.5 & 34.2 & 17.8 & 8.4 \\
Pressure $(\mathrm{hPa})$ & 730 & 996.2 & 1034.3 & 1013.0 & 8.7 \\
$\mathrm{RH}(\%)$ & 730 & 31.8 & 96.6 & 73.2 & 12.5 \\
$\mathrm{WS}(\mathrm{m} / \mathrm{s})$ & 730 & 0.1 & 4.8 & 1.7 & 0.8 \\
\hline
\end{tabular}

647

648

649

650

651

652

653

654 Table S2. Indices of classified variables in MCA.

\begin{tabular}{lcccccc}
\hline Categories & $\mathrm{CO}\left(\mathrm{mg} / \mathrm{m}^{3}\right)$ & $\mathrm{NO}_{2}\left(\mu \mathrm{g} / \mathrm{m}^{3}\right)$ & $\mathrm{PM}_{2.5}\left(\mu \mathrm{g} / \mathrm{m}^{3}\right)$ & $\mathrm{SO}_{2}\left(\mu \mathrm{g} / \mathrm{m}^{3}\right)$ & $\mathrm{P}(\mathrm{Pa})$ & Color \\
\hline 1 & $0-0.5$ & $0-20$ & $0-15$ & $0-10$ & $990-1010$ & blue \\
2 & $0.5-1$ & $20-40$ & $15-35$ & $10-20$ & $1010-1020$ & green \\
3 & $1-1.5$ & $40-60$ & $35-75$ & $20-40$ & $1020-1030$ & red \\
4 & $>1.5$ & $>60$ & $>75$ & $>40$ & $1030-1040$ & black \\
\hline Categories & $\mathrm{Vis}(\mathrm{km})$ & $\mathrm{RH}(\%)$ & $\mathrm{WS}(\mathrm{m} / \mathrm{s})$ & $\mathrm{T}\left({ }^{\circ} \mathrm{C}\right)$ & $\mathrm{O}_{3}\left(\mu \mathrm{g} / \mathrm{m}^{3}\right)$ & Color \\
\hline 1 & $0<\mathrm{V}<5$ & $<60$ & $0-1$ & $0-10$ & $0-40$ & black \\
2 & $5<\mathrm{V}<10$ & $60-80$ & $1-2$ & $10-20$ & $40-80$ & red \\
3 & $10<\mathrm{V}<15$ & $80-90$ & $2-3$ & $20-30$ & $80-120$ & green \\
4 & $\mathrm{~V}>15$ & $>90$ & $>3$ & $30-40$ & $>120$ & blue \\
\hline
\end{tabular}

655

656

657

658

659

660

661

662

663

664

665 
667 Table S3. The discrimination measures of the variables in MCA.

\begin{tabular}{|c|c|c|c|}
\hline & \multicolumn{2}{|c|}{ Dimension } & \multirow[b]{2}{*}{ Mean } \\
\hline & 1 & 2 & \\
\hline $\mathrm{CO}$ & 0.42 & 0.28 & 0.35 \\
\hline $\mathrm{NO}_{2}$ & 0.77 & 0.47 & 0.62 \\
\hline $\mathrm{PM}_{2.5}$ & 0.66 & 0.42 & 0.54 \\
\hline $\mathrm{SO}_{2}$ & 0.54 & 0.30 & 0.42 \\
\hline $\mathrm{O}_{3}$ & 0.14 & 0.18 & 0.16 \\
\hline WS & 0.10 & 0.14 & 0.12 \\
\hline $\mathrm{T}$ & 0.56 & 0.27 & 0.42 \\
\hline RH & 0.06 & 0.05 & 0.06 \\
\hline $\mathrm{P}$ & 0.59 & 0.24 & 0.41 \\
\hline $\mathrm{V}$ & 0.31 & 0.18 & 0.25 \\
\hline Total & 4.15 & 2.54 & 3.34 \\
\hline Variance $(\%)$ & 41.5 & 25.4 & 33.4 \\
\hline
\end{tabular}

668

669

670

671

672

673

674 Table S4. Pearson correlation coefficient of visibility and other environmental variables.

\begin{tabular}{|c|c|c|c|c|c|c|c|c|c|c|}
\hline & Visibility & $\mathrm{PM}_{2.5}$ & $\mathrm{CO}$ & $\mathrm{NO}_{2}$ & $\mathrm{SO}_{2}$ & $\mathrm{O}_{3}$ & WS & RH & $\mathrm{T}$ & $\mathrm{P}$ \\
\hline Visibility & 1 & & & & & & & & & \\
\hline $\mathrm{PM}_{2.5}$ & $-0.50^{* *}$ & 1 & & & & & & & & \\
\hline $\mathrm{CO}$ & $-0.51^{* *}$ & $0.68^{* *}$ & 1 & & & & & & & \\
\hline $\mathrm{NO}_{2}$ & $-0.47^{* *}$ & $0.70^{* *}$ & $0.54^{* *}$ & 1 & & & & & & \\
\hline $\mathrm{SO}_{2}$ & $-0.18^{* *}$ & $0.57^{* *}$ & $0.40^{* *}$ & $0.63^{* *}$ & 1 & & & & & \\
\hline $\mathrm{O}_{3}$ & $0.18^{* *}$ & $-0.14^{* *}$ & $-0.22^{* *}$ & $-0.39^{* *}$ & $-0.23^{* *}$ & 1 & & & & \\
\hline WS & $0.39^{* *}$ & $-0.26^{* *}$ & $-0.19^{* *}$ & $-0.27^{* *}$ & $-0.14^{* *}$ & 0.04 & 1 & & & \\
\hline RH & $-0.40^{* *}$ & $-0.22^{* *}$ & $-0.07^{*}$ & $-0.15^{* *}$ & $-0.40^{* *}$ & $-0.23^{* *}$ & $-0.20^{* *}$ & 1 & & \\
\hline $\mathrm{T}$ & $0.30^{* *}$ & $-0.45^{* *}$ & $-0.37^{* *}$ & $-0.65^{* *}$ & $-0.40^{* *}$ & $0.18^{* *}$ & $0.15^{* *}$ & $0.17^{* *}$ & 1 & \\
\hline $\mathrm{P}$ & $-0.18^{* *}$ & $0.43^{* *}$ & $0.33^{* *}$ & $0.62^{* *}$ & $0.43^{* *}$ & $-0.18^{* *}$ & $-0.19^{* *}$ & $-0.29^{* *}$ & $-0.89^{* *}$ & 1 \\
\hline Rainfall & $-0.13^{* *}$ & $-0.17^{* *}$ & $-0.08^{*}$ & $-0.13^{* *}$ & -0.07 & $-0.14^{* *}$ & -0.02 & $0.36^{* *}$ & $0.11^{* *}$ & $-0.17^{* *}$ \\
\hline
\end{tabular}
*Correlation is significant at the 0.05 level (two-tailed). ${ }^{* *}$ Correlation is significant at the 0.01 676 level (two-tailed). 


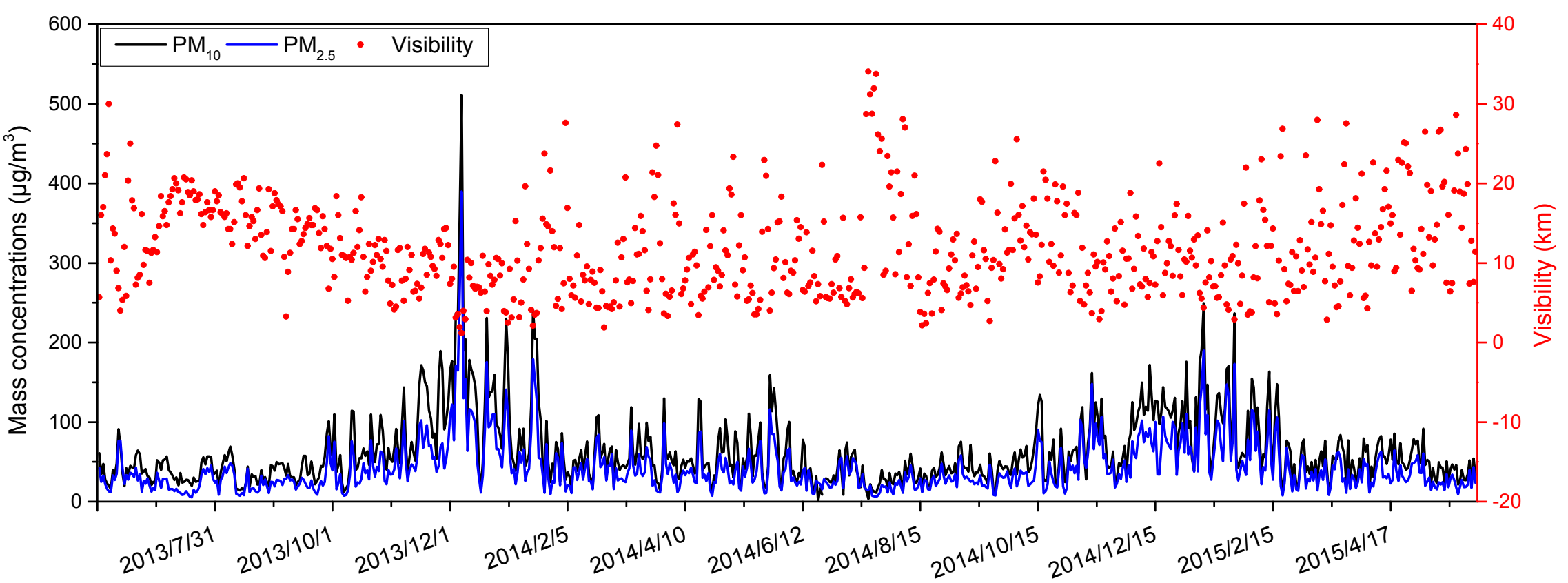

678

Fig. S1. Day-to-day variations of visibility, $\mathrm{PM}_{2.5}$ and $\mathrm{PM}_{10}$ from June, 2013 to May, 2015 at DQL station in Ningbo. 

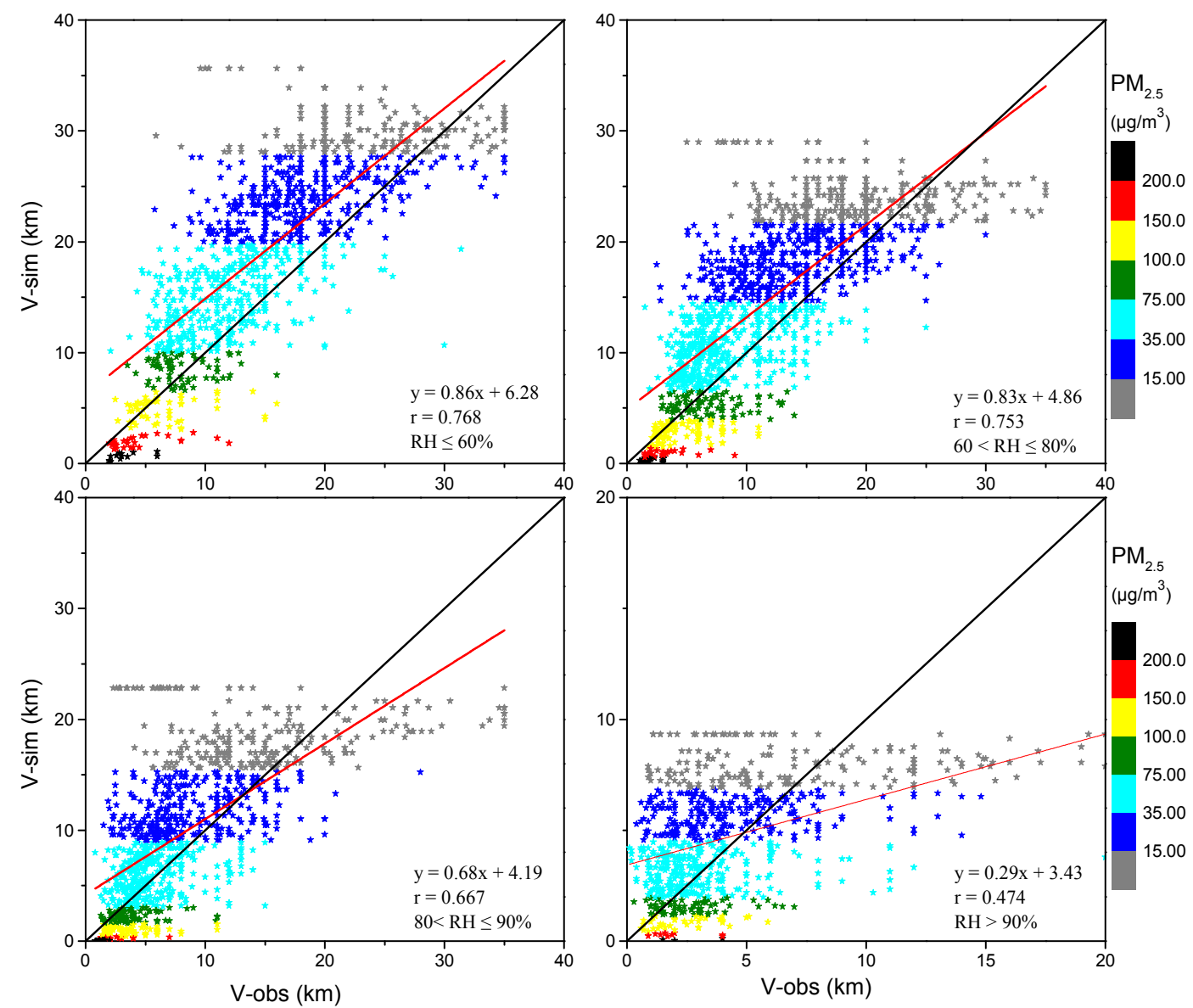

Fig. S2. Comparison between the observed hourly visibility and exponential equation (3) simulated hourly visibility during 2013.6-2014.5.

(V-obs: the observed visibility; V-sim: the simulated visibility). 
Editorial Department

P. O. Box 2871

Beijing 100085

China

Tel: 86-10-62920553

E-mail: jesc@rcees.ac.cn

\section{Journal Publishing Agreement}

Author(s): Jingjing zhang, LeiTong, Chenghui, Peng, Huiling, zhang, zhongwen, Huang, Jun He, Hang xiao

Title:

\section{Temporal variability of Visibility and its parameterizations in Ningbo, China.}

The undersigned authors, with the consent of all authors, hereby assign to Journal of Environmental Sciences, the copyright in the above identified article to be transferred, including supplemental tables, illustrations or other information submitted in all forms and media throughout the world, in all languages and format, effective when and if the article is accepted for publication.

Authors also agree to the following terms:

A. The article submitted is not subject to any prior claim or agreement and is not under consideration for publication elsewhere.

B. The article contains no libelous or other unlawful statements and does not contain any materials that violate proprietary right of any other person, company, organization, and nation.

C. If the article was prepared jointly with other authors, the author(s) agree with the authorship sequence.

Please sign and date the document.

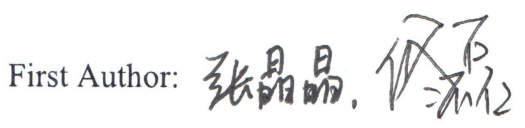

Date:

2018.3 .22

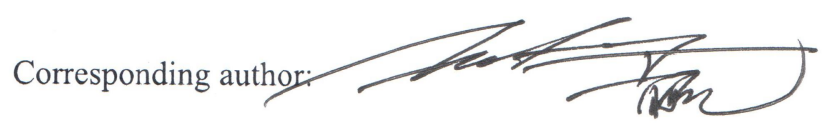

Date:

$20 / 8.3 .22$. 